\title{
Article \\ Computed Tomography in Limb Salvage and Deformity Correction-3D Assessment, Indications, Radiation Exposure, and Safety Considerations
}

\author{
Lukas Zak *(D), Thomas M. Tiefenboeck (D) and Gerald E. Wozasek
}

check for

updates

Citation: Zak, L.; Tiefenboeck, T.M.; Wozasek, G.E. Computed

Tomography in Limb Salvage and

Deformity Correction-3D

Assessment, Indications, Radiation Exposure, and Safety Considerations. J. Clin. Med. 2021, 10, 3781. https:// doi.org/10.3390/jcm10173781

Academic Editors: Emmanuel Andrès and Christian Carulli

Received: 19 May 2021

Accepted: 18 August 2021

Published: 24 August 2021

Publisher's Note: MDPI stays neutral with regard to jurisdictional claims in published maps and institutional affiliations.

Copyright: (C) 2021 by the authors. Licensee MDPI, Basel, Switzerland. This article is an open access article distributed under the terms and conditions of the Creative Commons Attribution (CC BY) license (https:/ / creativecommons.org/licenses/by/ $4.0 /)$.
Department of Orthopedics and Trauma-Surgery, Trauma Surgery, Medical University of Vienna, Waehringer Guertel 18-20, 1090 Vienna, Austria; thomas.tiefenboeck@meduniwien.ac.at (T.M.T.); gerald.wozasek@meduniwien.ac.at (G.E.W.)

* Correspondence: lukas.zak@meduniwien.ac.at

\begin{abstract}
Computed tomography (CT) is an essential tool in orthopedic surgery but is known to be a method with that entails radiation exposure. CT increases the risk of developing fatal cancer, which should not be underestimated. However, patients with bone defects and/or deformities must frequently undergo numerous investigations during their treatment. CT is used for surgical planning, evaluating callus maturation, alignment measurement, length measurement, torsion measurement, and angiography. This study explores the indications in CT scans for limb lengthening and deformity correction and estimates the effective radiation dose. These results should help avoid unnecessary radiation exposure by narrowing the examination field and by providing explicit scanning indications. For this study, 19 posttraumatic patients were included after the bone reconstruction of 21 lower limbs. All patients underwent CT examinations during or after treatment with an external ring fixator. The mean effective dose was $3.27 \mathrm{mSv}$, with a mean cancer risk of 1:117,014. The effective dose depended on the location and indication of measurement, with a mean dose of $0.04 \mathrm{mSv}$ at the ankle up to $6.8 \mathrm{mSv}$ (or higher) for vascular depictions. CT evaluation, with or without 3D reconstruction, is a crucial tool in complex bone reconstruction and deformity treatments. Therefore, strict indications are necessary to reduce radiation exposure-especially in young patients—without compromising the management of their patients.
\end{abstract}

Keywords: CT; deformity correction; distraction osteogenesis; external ring fixation

\section{Introduction}

Injuries of the lower limb are common in high-energy traumata and are often accompanied by open fractures with large bone defects and soft tissue injuries [1]. In these cases, various radiological evaluation methods, such as conventional radiography, computed tomography (CT), (color flow) Doppler ultrasound, digital subtraction angiography, and computed tomography angiography (CTA) are crucial. These methods may be necessary for emergencies, complication assessments, presurgical planning, and decision-making in bone reconstruction [2].

Computed tomography has become the method of choice to detect bone pathologies and lesions as well as subtle or non-displaced fractures, in instances where conventional radiographs have limitations [3]. The last decade's developments enabled the acquisition of three-dimensional data sets with a submillimeter spatial resolution, facilitating the creation of high-speed detailed image reconstruction and display techniques [2].

Spiral CT in-plane slides, or 3D reconstructions, have become the preferred imaging modality for orthopedic patients with various indications [4]. This method offers a variety of advantages, such as fast scan time, high resolution, and good availability [5]. The rapid generation of 3D data sets can immediately display the results on the screen, enabling quick interpretations and demonstrations for clinicians [5]. In emergency cases, CTA is a 
reliable technique for traumatic arterial injury diagnosis in the extremities [6]. This method also helps medical professionals select patients for interventional radiologic procedures [2] and plan microsurgical reconstructions [7].

High-resolution and powerful computers are necessary for 3D postprocessing and $3 \mathrm{D}$ reconstruction in trauma and orthopedic surgery. This method's areas of application include posttraumatic intraosseous rotation of the scaphoid, [8] planning in maxilla-fascial surgery, [9] angiographic depictions, [10] angiographic planning for soft tissue flaps, [11] and planning for complex injuries [4] or various pathological conditions masked by metal artifacts $[4,12]$.

This study aimed to present the various indications for CT scans in limb salvaging, bone reconstruction, and deformity correction. To our knowledge, no published study on this topic has estimated the effective dose of radiation or the risk of developing fatal cancer. The discussion of differences between deformities, indications, locations, ages, and genders highlights the necessity of safe and effective imaging.

We hypothesized that patients with lower limb deformities would receive higher radiation exposure during treatment than healthy patients, resulting in a highly increased risk for induced fatal cancer.

\section{Patients and Methods}

\subsection{Patients}

All procedures involving human participants followed the ethical standards of the institutional ethical review board (Nr. 1054/2016), along with the 1964 Helsinki Declaration and its later amendments (or comparable ethical standards).

For this retrospective study, we reviewed our departmental database for patients with posttraumatic bone defects or shortening of the bone. At our Trauma Department, between 2006 and 2015, 25 patients underwent bone reconstruction surgeries and limb lengthening via treatment with an external ring fixator for bone lengthening, bone transport, and axis correction. This study included 19 patients with 21 treated extremities evaluated by $\mathrm{CT}$ scans for planning and follow-up. Both open and closed fractures were primarily or secondarily treated with a Taylor Spatial Frame (TSF, Smith and Nephew, Memphis, TN, USA) (19 extremities) or an Ilizarov frame (2 extremities). Patients suffered from motor vehicle accidents (MVAs), motorcycle accidents (MCAs), industrial accidents (IAs), falls from a great height, gunshot fractures (GSFx), or other accidents. These traumas resulted in bone loss, bone shortening, pseudarthrosis, bone infection, or axial deviation. The patient characteristics and pre-history are presented in Table 1 and a list of all patients in Table 2. Six patients were excluded, as no CT scans were performed during their observation periods. Further exclusion criteria included pediatric or adult non-traumatic deformity correction, as well as patients treated by intramedullary lengthening.

Table 1. Patient characteristics, mean \pm SD (range); $M$, male; F, female; TSF, Taylor Spatial Frame; MVA, motor vehicle accident; tib-fib, tibial-fibular.

\begin{tabular}{cc}
\hline \multicolumn{2}{c}{ Patient Characteristics } \\
\hline $\mathbf{N}$ & $\begin{array}{c}19 \text { patients } \\
21 \text { extremities }\end{array}$ \\
\hline Demographic data & \\
\hline Age (years) & $44 \pm 20(15-82)$ \\
\hline $\mathrm{M}$ & $37 \pm 15.6(15-73)$ \\
\hline $\mathrm{F}$ & $61 \pm 19.5(27-82)$ \\
\hline Sex $(\mathrm{M} / \mathrm{F})$ & $13 / 6$ \\
\hline
\end{tabular}


Table 1. Cont.

\begin{tabular}{cc}
\hline \multicolumn{1}{c}{ Patient Characteristics } \\
\hline Baseline characteristics & $2 / 19$ \\
\hline Ring fixator/TSF & 19 patients \\
\hline Trauma & 11 \\
\hline MVA & 2 \\
\hline Industrial accident & 4 \\
\hline Fall & 2 \\
\hline Gunshot accident & 4 \\
\hline Deformity & 5 \\
\hline Pseudarthrosis & 4 \\
\hline Bone defect/shortening & 5 \\
\hline Axial deviation & 1 \\
\hline Axis + shortening & 21 extremities \\
\hline Osteomyelitis & 14 \\
\hline Location & 1 \\
\hline Open tib-fib fracture & 2 \\
\hline Open femur fracture & 1 \\
\hline Prox tibial fracture & 3 \\
\hline Ankle Fracture & \\
\hline Tib-fib Gunshot fracture & \\
\hline
\end{tabular}

Table 2. List of all patients, including age, gender, location on the lower limb, trauma anamnesis, type of fracture, and treated type of deformity.

\begin{tabular}{|c|c|c|c|c|c|c|}
\hline \multicolumn{7}{|c|}{ Patient's List } \\
\hline & Age & Sex & Location & Accident & Fracture & Treatment \\
\hline 1 & 49 & $\mathrm{~m}$ & tib-fib & MVA/MC & open Fx & PA, bone transport Ilizarov \\
\hline 2 & 40 & $\mathrm{~m}$ & tib-fib & MVA/MC & open Fx & PA, bone transport TSF over nail \\
\hline 3 & 70 & $\mathrm{f}$ & tib-fib & Fall & open Fx & PA, axial deviation, vessel lesion, TSF \\
\hline 4 & 18 & $\mathrm{~m}$ & tib-fib & Industrial a. & open Fx & bone defect, shortening, Ilizarov \\
\hline 5 & 34 & $\mathrm{~m}$ & tib-fib & MVA & open Fx & bone defect and soft tissue, PA, TSF \\
\hline 6 & 36 & $\mathrm{~m}$ & tib-fib/tib-fib & Gunshot & GSFx/GSFx & $\begin{array}{l}\text { left bone defect and refracture TSF, right } \\
\text { axial deviation }\end{array}$ \\
\hline 7 & 45 & $\mathrm{~m}$ & tib-fib & MVA/MC & prox tib Fx & axial deviation and shortening, TSF \\
\hline 8 & 50 & $\mathrm{~m}$ & tib-fib & MVA & prox tib Fx & axial deviation and shortening, TSF \\
\hline 9 & 15 & $\mathrm{~m}$ & tib-fib+femur & MVA/MC & open Fx & $\begin{array}{l}\text { huge bone defect, shortening, bone } \\
\text { transport and lengthening, TSF }\end{array}$ \\
\hline 10 & 73 & $\mathrm{~m}$ & tib-fib & Gunshot & GSFx & axial deviation and shortening, TSF \\
\hline 11 & 32 & $\mathrm{~m}$ & tib-fib & MVA/MC & open Fx & bone defect and shortening, TSF \\
\hline 12 & 31 & $\mathrm{~m}$ & tib-fib & IA. & open Fx & shortening, TSF \\
\hline 13 & 32 & $\mathrm{~m}$ & tib-fib & MVA & open Fx & axial deviation and shortening, TSF \\
\hline 14 & 27 & $\mathrm{f}$ & tib-fib & MVA (ped.) & open Fx & deux etage, healing in TSF \\
\hline 15 & 20 & $\mathrm{~m}$ & tib-fib & Fall & open Fx & osteomyelitis and fistulation, TSF \\
\hline 16 & 67 & $\mathrm{f}$ & tib-fib & Fall & ankle Fx & axis correction and arthrodesis TSF \\
\hline 17 & 50 & $\mathrm{f}$ & tib-fib/tib-fib & Fall & open Fx & axial deviation and shortening, TSF \\
\hline 18 & 82 & $\mathrm{f}$ & tib-fib & MVA (ped) & open Fx & axial deviation, TSF \\
\hline 19 & 70 & $\mathrm{f}$ & tib-fib & $\mathrm{MVA} / \mathrm{MC}$ & open Fx & axial deviation, TSF \\
\hline
\end{tabular}

F-female; $\mathrm{m}$-male; MVA-motor vehicle accident; MC—-motorcycle; tib-fib fx-tibial and fibular fracture; IA-industrial accident; PA—Pseudarthrosis; ped.—pedestrian; FfH—fall from height; TSF-Taylor Spatial Frame. 
Patients were evaluated during emergency care, preoperatively after initial damage control orthopedic (DCO) treatment (CT angiography, torsion measurement), during treatment for the evaluation of callus maturation to assess appearance, and during the healing of pseudarthrosis to measure alignment (or for follow up).

\subsection{CT Evaluation}

We used two different CT Scanners during the measurement period: a Siemens Somatom (Sensation Open, 64 slices, Siemens, Forchheim, Germany) and a Siemens Sensation 4 (Siemens, Forchheim, Germany).

Images were read on our PACS System (IMPAX EE, 2018 Agfa-Gevaert Group, Mortsel, Belgium) using the Volume Rendering Technique (VRT) software (IMPAX EE, 2018 AgfaGevaert Group, Mortsel, Belgium) employed for multidimensional image processing and computer viewing (in some cases).

When CT angiography of the pelvis and lower extremities was performed, an intravenous contrast agent (OptirayTM $350 \mathrm{mg} \mathrm{J} / \mathrm{mL}$, MallinckrodtTM Pharmaceuticals, Hennef, Germany) of $120 \mathrm{~mL}$ was applied.

The overall image quality was graded as excellent, good, fair, or poor, as adapted from Adibi et al. [2].

\subsection{Radiation Exposure}

The Effective Dose (ED) in millisieverts (mSv) was calculated by multiplying the doselength product (DLP) by the body-region-specific conversion coefficient $\mathrm{k}$ : "E $=\mathrm{k} * \mathrm{DLP}$ " [13] DLP was determined from the protocol of every CT scan, and the coefficient " $\mathrm{k}$ " was used as a specific weighting factor for the tissue, evaluated on a phantom model considering the scanned region and the patients' ages and genders [14].

Based on the ED, patient age, and patient gender, the estimated risk of radiationinduced fatal cancer (RFC) can be measured. For this purpose, we used the probability coefficient of an adult population with an age range of 25 to 64 years (mean 45 years), [15] according to the 1990 Recommendations of the International Commission on Radiological Protection (ICRP), [16] which was updated in 2007 [17]. The RFC corresponds to 1 in 25 patients after exposure to $1 \mathrm{~Sv}(1000 \mathrm{mSv})$ [15].

For individual gender- and age-related patient RFCs, we used the nominal probability coefficients for stochastic radiation effects of the ICRP, as presented in Cross et al. [15].

\subsection{Indications}

\subsubsection{CT Angiography}

CT angiography (CTA) or VRT was indicated for presurgical planning after dislocated fractures or significant bone defects to show vascular injury in axial views, in order to decide between limb salvage and amputation based on the course of the large vessels. An example is shown in Figure 1. Another indication was to follow-up after vascular repair and other vascular interventions to detect vascular stenosis or narrowing.

\subsubsection{Non-Union Evaluation}

For pseudarthrosis and non-union evaluation, a CT scan is essential for further planning. A helpful tool for pseudarthrosis and non-union evaluation is VRT, which can provide a three-dimensional representation of the bone (Figure 2). In this method, the illustrated metal parts of the external frame or cast can be removed from the picture to better understand the region of interest. The callus patency can then be evaluated, and the decision to engage in fixator removal can be made when three cortices are healed [18]. 


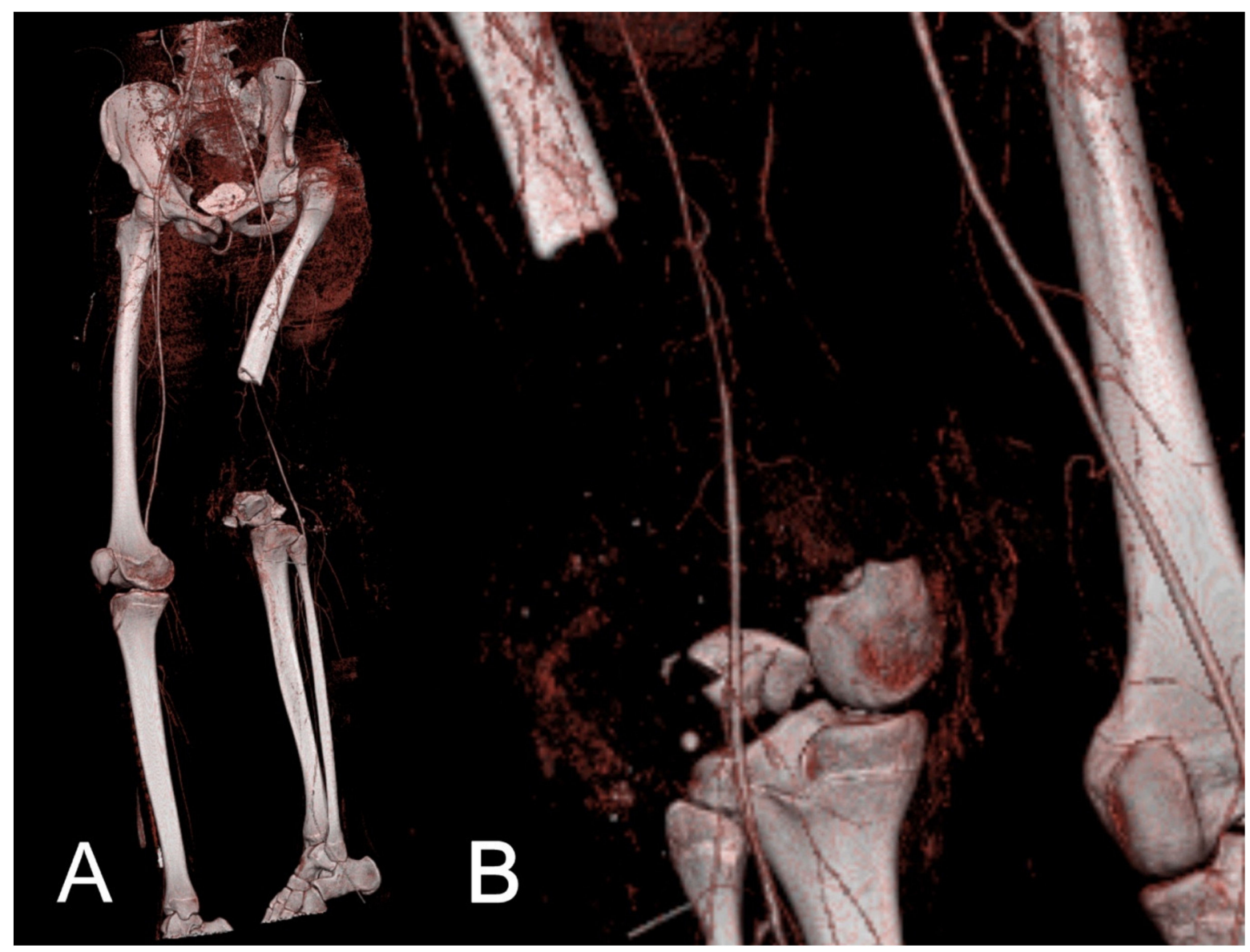

Figure 1. Massive bone defect in a 15-year-old patient on the left distal femur. Angiography was performed to decide between reconstruction and amputation and to plan the surgery. Oblique-anterior view. (A) The femoral artery has a reduced caliber but remains intact with a continuous flow. (B).
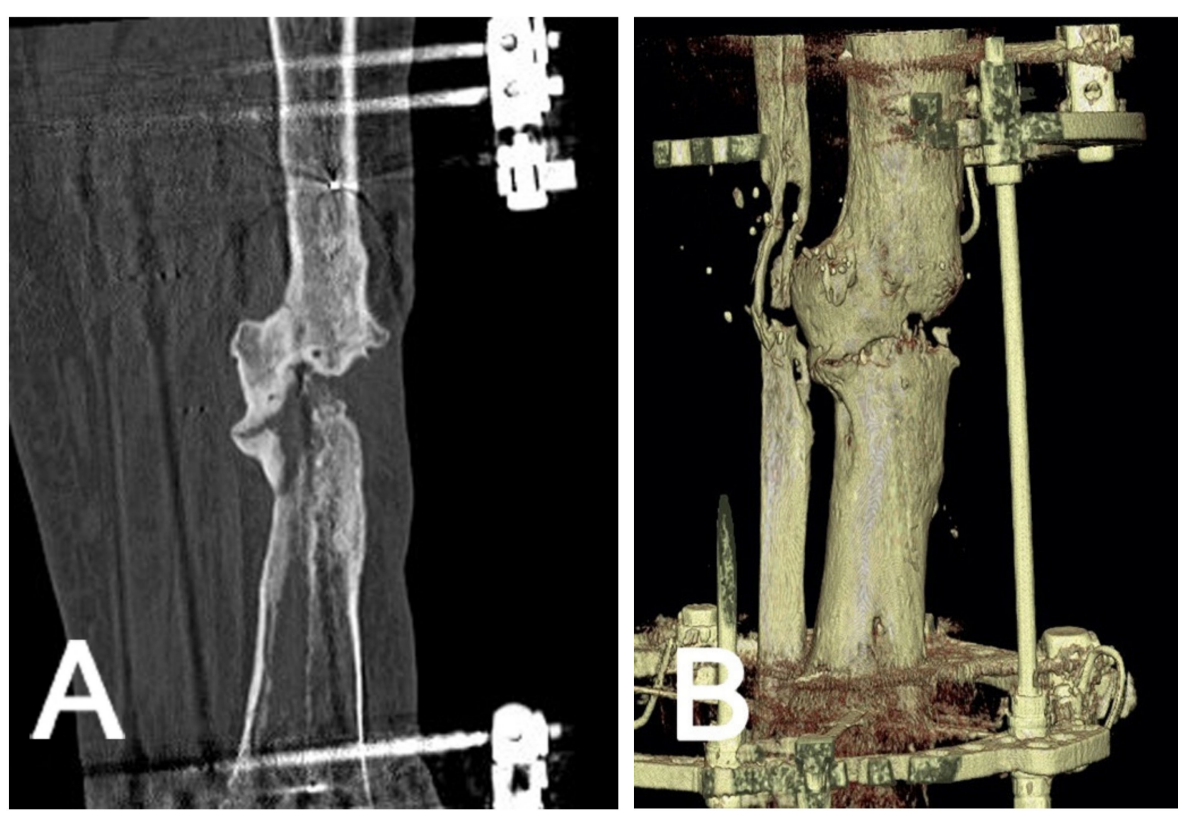

Figure 2. Non-union evaluation in a tibial bone with a 2D (A) and 3D view (B). 


\subsubsection{Axis and Alignment}

For axis and alignment measurements, CT scans with 2D and 3D representations are able to provide images of the bone from all angles (Figure 3). Correction planning in simple external fixators or ring fixators can then be performed, and planning schedules can be adapted according to the new data.
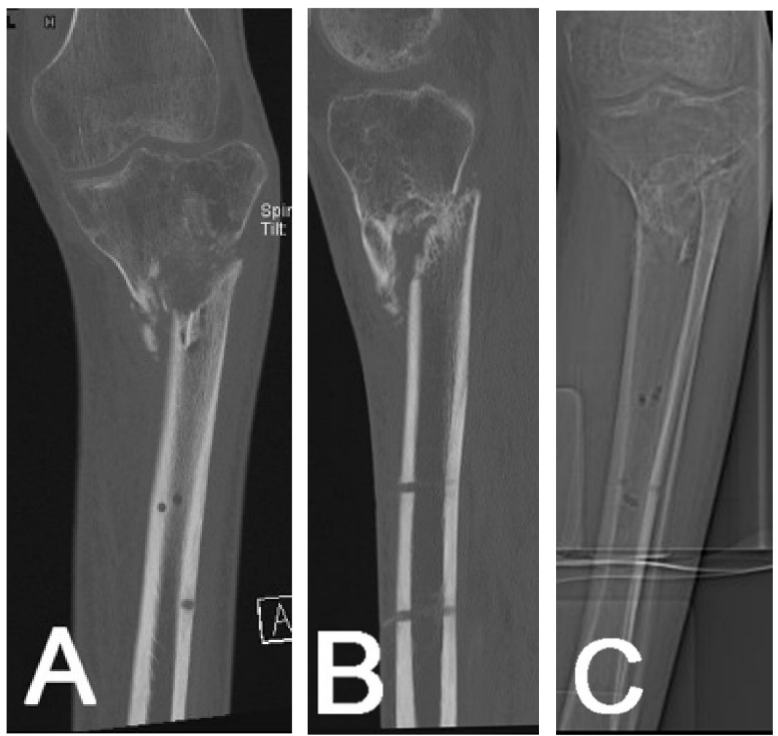

Figure 3. Conventional CT scan to plan deformity correction in a displaced proximal tibial fracture2D AP view (A) and lateral view (B) showing translation and varus deformity. Scanogram from the same patient in AP view (C).

\subsubsection{Surgical Planning}

Besides the planning of non-union treatment and axis correction, further interventions were planned through CT and VRT. Presurgical evaluation of complex fractures was performed to plan ring fixator assembly and axial malalignment. For this purpose, the amount of bone loss was illustrated in 2D or 3D for different strategies (Figure 4). CT scans can support the decision to engage in fixator removal if three intact cortices are visible [18], as measured on two planes in the 2D view or depicted in the VRT. To evaluate callus maturation, in some cases, external frames or casts were removed by the software (Figure 4B).
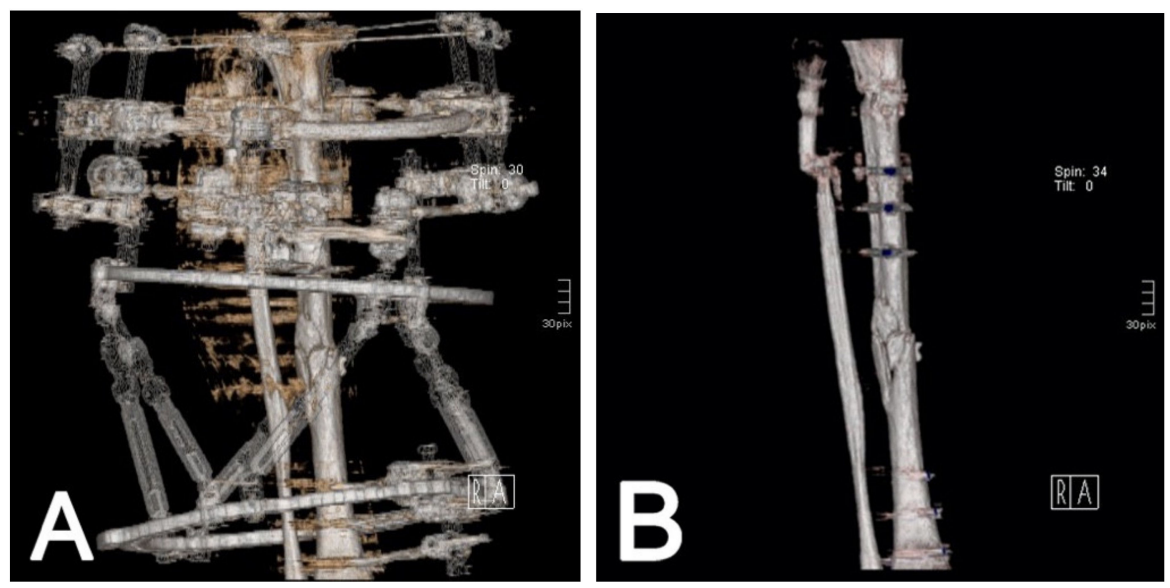

Figure 4. Three-dimensional reconstruction of the bone for planning. Artifacts and fixators can interfere with visibility in the region of interest (A) but can be removed by the software (B). 


\subsubsection{Leg Length Measurement}

The leg length was measured using a CT scanogram [19]. (Siemens Sensation Open, Figure 5) in lieu of the conventional alignment views commonly employed in the scanogram technique [19]. (Philips Medical System Digital Diagnost). This method facilitated more precise evaluations for presurgical planning. The correct length for customized arthrodesis nails or implants was measured via this method, and limb length discrepancies were evaluated to determine the distraction schedule.

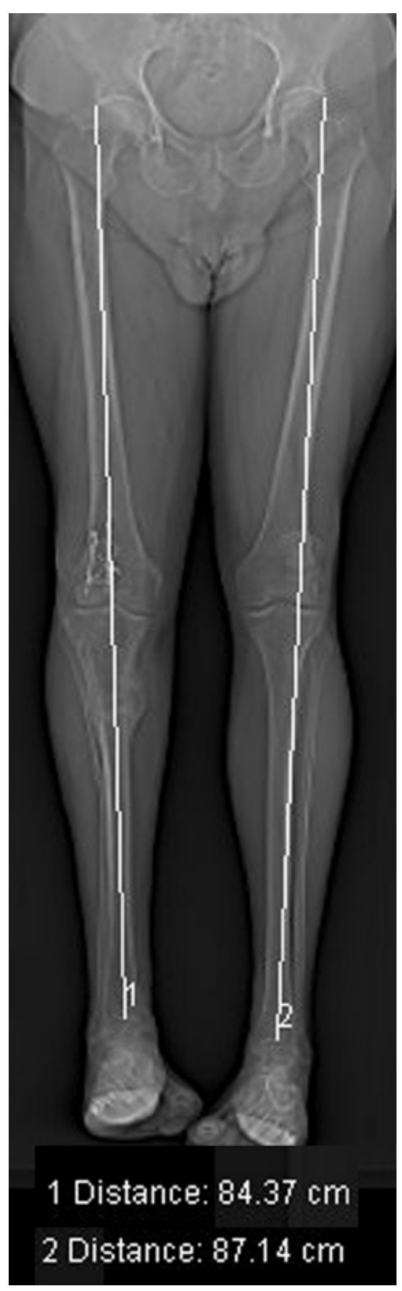

Figure 5. Length measurement of the lower limb to plan bone-lengthening surgery. The measurement shows a $2.8 \mathrm{~cm}$ LLD.

\subsubsection{Rotational CT/Torsion CT}

For rotational alignment measurement/lower limb torsion measurement, three acquisition zones were defined on an anterior-posterior (ap) scout view including the hip, knee, and ankle (Figure 6).

Femoral and tibial torsion measurements are usually performed using axial CT images [20]. to evaluate the rotational malalignment between the injured and non-injured extremity. 


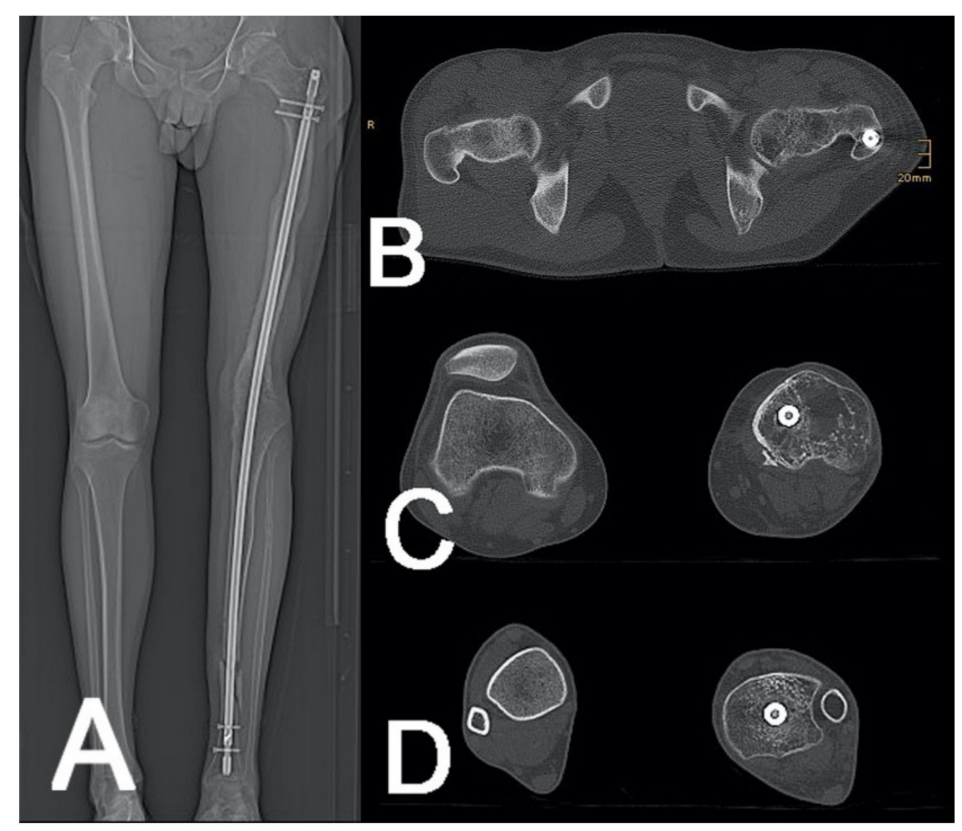

Figure 6. Rotational CT to plan the de-rotation surgery of a knee arthrodesis nail (A). Measurements of the hip (B), knee (C), and ankle joint (D) were performed.

\section{Results}

Treatment decisions were made according to the depictions of vessels, types of fracture, alignments, callus maturation, and rotation. Table 3 shows the distribution of the scans, specific questions, and indications. In total, $34 \mathrm{CT}$ scans were performed on 19 patients. In 12 out of 23 conventional CT scans and 6 out of 8 angiographic CT scans, a VRTreconstruction helped to answer specific questions for posttraumatic deformity correction. In most cases, more than one problem was analyzed for further therapeutic planning.

Table 3. List of all measurements, including the scans and indications for the scans; LLD, Limb length discrepancy.

\begin{tabular}{cc}
\hline Scans and Indications & \\
\hline Scans & 34 \\
Total & $23(12$ VRT $)$ \\
CT & 2 \\
Hip & 3 \\
Knee & 4 \\
Knee + lower leg & 8 \\
Lower leg & 3 \\
Lower leg + Ankle & 3 \\
Ankle & $8(6$ VRT $)$ \\
Angio CT & 2 \\
Rotational CT & 1 \\
CT scanogram & 48 \\
Vessels & 8 \\
Non-union & 10 \\
Axis & 4 \\
Specific questions/indications & 9 \\
Pre-/Further surgical planning & 5 \\
Fixator removal/Callus maturation & 5 \\
Length measurement, LLD & 7 \\
Malrotation & 13 \\
Mixed Indications & \\
\hline SD Standard deviation &
\end{tabular}


The results for the patients' effective doses and risk of fatal cancer are presented in Table 5, showing a mean risk of 1 in 213,920 per patient, based on the individual probability coefficient, or 1 in 117,014 for an average adult patient. These vast differences are a result of age and gender differences. A 2.3-fold risk for the youngest patients and $20 \%$ risk for the oldest patients were observed.

The ED depends on the indication of measurement and the location. The mean ankle measurement for an average adult person starts at 0.04 to $0.12 \mathrm{mSv}$ and rises to $6.8 \mathrm{mSv}$ or higher for vascular depictions in CTA. Here, the RFC ( 1 in 25 per $1 \mathrm{~Sv}$ ) increased from 1 in 700,000 to 1 in 5000 (Tables 4 and 5).

Table 4. Patient list with measured effective dose (ED), risk of induced fatal cancer (RFC) per Sv (1000 mSv), individual patient-specific risk, and risk for an adult person (1 in 25 per Sv).

\begin{tabular}{|c|c|c|c|c|c|c|c|}
\hline \multicolumn{8}{|c|}{ Effective Dose and RFC_Patients } \\
\hline & Age & Sex & Nr. CTs & ED (mSv) & RFC Per Sv & $\begin{array}{c}\text { RFC } \\
\text { (Individual) }\end{array}$ & $\begin{array}{c}\text { RFC } \\
\text { (Adult) }\end{array}$ \\
\hline 1 & 49 & $\mathrm{~m}$ & 2 & 2.21 & 1 in 24 & 10,860 & 11,312 \\
\hline 2 & 40 & $\mathrm{~m}$ & 2 & 0.16 & 1 in 24 & 151,052 & 157,346 \\
\hline 3 & 70 & $\mathrm{f}$ & 7 & 37.60 & 1 in 62 & 1649 & 665 \\
\hline 4 & 18 & $\mathrm{~m}$ & 1 & 4.95 & 1 in 11 & 2222 & 5051 \\
\hline 5 & 34 & $\mathrm{~m}$ & 1 & 5.15 & 1 in 23 & 4468 & 4856 \\
\hline 6 & 36 & $\mathrm{~m}$ & 3 & 2.72 & 1 in 23 & 8464 & 9200 \\
\hline 7 & 45 & $\mathrm{~m}$ & 1 & 0.19 & 1 in 24 & 129,450 & 134,844 \\
\hline 8 & 50 & $\mathrm{~m}$ & 2 & 0.28 & 1 in 24 & 86,331 & 89,928 \\
\hline 9 & 15 & $\mathrm{~m}$ & 2 & 5.93 & 1 in 11 & 1856 & 4217 \\
\hline 10 & 73 & $\mathrm{~m}$ & 1 & 0.11 & 1 in 59 & 561,905 & 238,095 \\
\hline 11 & 32 & $\mathrm{~m}$ & 1 & 0.34 & 1 in 23 & 67,548 & 73,421 \\
\hline 12 & 31 & $\mathrm{~m}$ & 2 & 0.22 & 2 in 23 & 102,679 & 111,607 \\
\hline 13 & 32 & $\mathrm{~m}$ & 2 & 0.13 & 3 in 23 & 172,673 & 187,688 \\
\hline 14 & 27 & $\mathrm{f}$ & 1 & 0.29 & 1 in 14 & 48,110 & 85,911 \\
\hline 15 & 20 & $\mathrm{~m}$ & 1 & 0.12 & 1 in 16 & 130,081 & 203,252 \\
\hline 16 & 67 & $\mathrm{f}$ & 1 & 0.06 & 1 in 34 & 570,470 & 419,463 \\
\hline 17 & 50 & $\mathrm{f}$ & 4 & 1.44 & 1 in 26 & 18,038 & 17,344 \\
\hline 18 & 82 & $\mathrm{f}$ & 1 & 0.10 & 1 in 143 & $1,471,193$ & 257,202 \\
\hline \multirow[t]{2}{*}{19} & 70 & $\mathrm{f}$ & 1 & 0.12 & 1 in 62 & 525,424 & 211,864 \\
\hline & & & & 3.27 & 1 in 34 & 213,920 & 117,014 \\
\hline
\end{tabular}

Table 5. Effective Dose (ED) and risk of fatal cancer (RFC, 1 in X) in various indications and locations for an average adult worker.

\begin{tabular}{ccc}
\hline \multicolumn{3}{c}{ Effective Dose and Risk of Fatal Cancer } \\
\hline Specific Questions/Indications & Mean ED & RFC \\
Vessels (CTA) & 6.80 & 3677 \\
Non-union & 0.49 & 51,502 \\
Axis & 0.20 & 123,793 \\
Pre-/Further surgical planning & 0.29 & 87,054 \\
Fix. Removal/Callus maturation & 0.10 & 250,479 \\
Length measurement, LLD & 0.38 & 66,246 \\
Malrotation & 2.34 & 10,701 \\
Location & & \\
CTA & 5.04 & 4956 \\
Topo & 0.19 & 134,844 \\
Hip & 2.54 & 9825 \\
Knee & 0.10 & 262,608 \\
Knee + lower leg & 0.21 & 118,147 \\
Lower leg & 0.18 & 140,417 \\
Lower leg + Ankle & 0.12 & 217,050 \\
Ankle & 0.04 & 692,252 \\
\hline
\end{tabular}


The mean quality, according to the classification of Adibi et al., was 3.4 for the CT scans and 3.1 for the VRT presentation. In $88.2 \%$ of CT measurements and 75\% of VRT measurements, the image quality was graded as good to excellent, and external fixators or casts did not influence accessibility. The CTA quality was graded as 3.3 and the CTA VRT quality as 3.0, indicating at least good diagnostic potential for arterial injuries.

\section{Discussion}

The present work aimed to describe indications for CT scans in limb reconstruction and deformity correction based on a case study evaluating the quality and dose effects in various indications. Furthermore, this paper examined the risk of radiation exposure among this specific patient population. To our knowledge, no other study in this field has analyzed or highlighted this issue.

CT bone scanning of the extremities has a significantly higher effective dose than that of conventional radiography but entails considerably lower radiation exposure than investigations of the trunk region. [14,15].

For conventional x-rays of the extremities, an average effective dose of 0.001 to $0.005 \mathrm{mSV}$ per series is expected [21]. In contrast, a CT-scan of the lower limbs created amounts of 0.0013 (CT ankle joint) to $6.63 \mathrm{mSV}$ (CT angiography of a female) in our series, depending on the modality and issue.

Alternative methods that use no radiation, such as ultrasound and MRI, are available with limitations. Indeed, as most modern commercial fracture fixation implants do not contain any ferromagnetic materials, magnetic resonance imaging (MRI) is commonly used as an alternative assessment method for long bones [22,23]. The advantage of MRI is its ability to depict soft-tissue abnormalities adjacent to the pathology [24]. Ultrasound can also be used to evaluate callus maturation but is disadvantageous in detecting angulation [25].

Both methods do not have the ability to create 3D reconstructions. The volumetric rendering technique (VRT) enhances the visualization of pathologies and helps to handle large data sets. VRT effectively shows subcortical lesions, minimally displaced fractures, and hidden areas of interest [10]. This technique can reduce visible streak artifacts, even in the presence of metal implants, pins, or prostheses. [4,10]. Various practical algorithms and reconstruction techniques are also available [26]. The most common indications are CTA (Figure 1), non-union evaluation (Figure 2), and surgical planning (Figure 4). In emergency situations, a standard procedure has been developed to detect and characterize traumatic arterial injuries of the extremities using CTA [6]. This procedure is non-invasive and allows one to measure different areas of the body simultaneously [6]. CT has also been used to determine fracture stability [27] and rotational malalignments [28,29]. and seems to be superior to conventional radiographs for non-union evaluations, as CT is unaffected by abundant calluses or the presence of a cast [3]. However, CT's almost-100\% sensitivity contrasts with the low specificity of other techniques (62\% to $83 \%$ ) [30]. Complementary methods such as SPECT/CT scans are available with lower sensitivity but reasonable specificity that excludes infection and confirms the non-union site's nonviability [31].

For length measurements, CT scanograms $(0.6 \mathrm{mS})$ were described as being more accurate and requiring fewer radiation doses than computed radiography (CR) scanograms, with three large exposures used for the hip, knee, and ankle ( $2 \mathrm{mSv})$ in a pediatric patient population [19]. CR can capture the entire femoral and tibial length and minimize measurement errors $[19,32]$. Sabharwal et al. evaluated 111 patients with LLD using a CR-based scanogram and teleoroentgenogram. Ultimately, 4.6\% (33 mm) magnification was measured for the lower extremity's absolute length using a standing radiograph, with a mean difference of $5 \mathrm{~mm}$ in the LLD measurement between the two CR techniques $[19,33]$. Among our patients, we discovered two faulty presurgical planning cases using conventional long axial views. We replaced this method in individual cases with a CT topogram $(0.19 \mathrm{mSv})$, showing discrepancies between $2.9 \%$ and $3.7 \%$. These differences can lead to severe consequences in the planning and performance of orthopedic surgery. 
For our risk calculations, the calculated effective dose was based on the measured DLP and the $k$-values of a phantom model, with the disadvantage of not considering the individual patient-specific habitus [14]. The scanner was from the same company (in both studies) [14,34], as we expected comparable values. The effective dose depends on the scanner, scanning area, and gender. [14,17].

Cross et al. [15] reported a radiation exposure of $0.5 \mathrm{mSv}$ for knee and foot/ankle measurements, whereas Koivisto et al. presented values of $0.021 \mathrm{mSv}$, which are comparable with our results (Table 4). The ED of the pelvic CT was reported with a mean value of $8 \mathrm{mSv}$ [35]. and the hip scan with a mean value of $3.09 \mathrm{mSv}$. These results refer to multiple doses of foot and lower-leg scans, with EDs of $0.16 \mathrm{mSv}$ (knee) and $0.07 \mathrm{mSv}$ (ankle) [36]. These values are comparable to those in our study, which combined knee and knee/proximal lower leg $(0.14 \mathrm{mSv})$ or ankle and ankle/distal lower leg $(0.08 \mathrm{mSv})$ measurements (Table 4).

The risk for inducing fatal cancer was calculated as 1 in 25 per $1 \mathrm{~Sv}$ (1000 mSv) for an adult worker to simplify measurements for the indication and location-specific statements. For patient-specific measurements, age and gender were also considered. The risk is more than twice as high for children and teenagers and about half as high for elderly patients around 70 years of age [15]. For adult women, the tissue-weighting factors and the risk of fatal cancer are the same as those for men for all tissues, except the breast [15].

In one case (Nr. 3), seven CT scans (mostly CTA) were performed to follow up on a vascular lesion with an individual high cancer risk of 1 in 1649 for a 70 year-old female patient. Nearly the same risk (1 in 1856) was measured for an adolescent patient with two necessary CTs (CTA and a hip-knee-ankle CT for rotational measurement), with a 5.6-fold higher risk per SV.

According to Kovacs et al., exposure during chest, abdominal, and pelvic examinations could be reduced by up to $50 \%$ by adapting protocols over a period of 5 years (2010-2015) — values that cannot be achieved for extremity scans [37]. However, recent technological advances and refined protocols have been developed to reduce radiation doses. A low-dose CT protocol for the purpose of surgical planning can strongly reduce radiation exposure compared to traditional CT without affecting image quality or diagnostic performance $[38,39]$. Contrast enhancement seems to be valuable only in the evaluation of soft-tissue structures [40]. As metal implants increase radiation exposure, [41] external ring fixators with carbon rings (TSF) and a higher amount of non-metal parts are advantageous compared to full metal devices.

The limitations of this study include its small patient number, retrospective design, and the absence of a control group without cast or metal devices.

In a few cases, metal artifacts severely influenced the CT or VRT evaluations of fracture or callus maturation. Metal implants not only deteriorate image quality but also increase radiation exposure [41]. This was not considered in our measurements, as measurements typically took place before metal implantation, and deformity correction was typically performed with a TSF.

MRI can serve as an alternative method entailing less radiation exposure and using compatible non-ferromagnetic external fixators with fewer noise artifacts [23]. under safe conditions [42]. Furthermore, in the present study, each particular scan time was not evaluated separately.

\section{Conclusions}

Patients with complex bone lesions and deformities may undergo numerous diagnostic medical investigations. CT scanning with or without 3D reconstruction is, therefore, a crucial tool and can be necessary to handle complications, to decide fixator removal, and/or to assess non-unions. CT is commonly applied with acceptable radiation exposure in various indications. However, medical professionals should remain aware of high radiation exposure in angiographic CT measurements of the pelvis and lower limbs. These measurements result in an increased risk of fatal cancer, especially in children, adolescents, 
and young adults. Therefore, the number of scans and regions of interest must be limited to the exact indications of $\mathrm{CT}$ examinations to protect patients from radiation absorption. This paper is intended to promote awareness and help orthopedic surgeons decide upon the use of CT scans for deformity correction, thereby avoiding unnecessary radiation exposure or pitfalls.

Author Contributions: L.Z. was responsible for the conceptualization, data curation, formal analysis, investigation, methodology, project administration, visualization, and writing. T.M.T. was the corresponding author for the conceptualization, methodology, review, and editing. G.E.W. was the senior author and accountable for the conceptualization, methodology, supervision, validation, writing, and review and editing. All authors have read and agreed to the published version of the manuscript.

Funding: This research received no external funding.

Institutional Review Board Statement: All procedures involving human participants followed the ethical standards of the institutional ethical review board (Nr. 1054/2016), along with the 1964 Helsinki Declaration and its later amendments (or comparable ethical standards).

Informed Consent Statement: Patient consent was waived due to the retrospective and descriptive nature of this study and de-identified data without any personal information.

Data Availability Statement: For this retrospective study, we reviewed our departmental database for patients with posttraumatic bone defects or shortening of the bone.

Conflicts of Interest: The authors declare no conflict of interest.

$\begin{array}{ll}\text { Abbreviations } \\ \text { CT } & \text { Computer Tomography } \\ \text { CTA } & \text { Computer Tomography Angiography } \\ \text { MVA } & \text { Motor vehicle accident } \\ \text { MCA } & \text { Motorcycle accident } \\ \text { IA } & \text { Industrial accident } \\ \text { GSFx } & \text { Gunshot fracture } \\ \text { TSF } & \text { Taylor Spatial Frame } \\ \text { DCO } & \text { Damage Control Orthopedics } \\ \text { tib-fib } & \text { tibial-fibular } \\ \text { Fx } & \text { Fracture } \\ \text { PA } & \text { Pseudarthrosis } \\ \text { ped. } & \text { Pedestrian } \\ \text { m } & \text { male } \\ \text { f } & \text { female } \\ \text { ED } & \text { Effective Dose } \\ \text { DLP } & \text { dose length product } \\ \text { VRT } & \text { Volume Rendering Technique } \\ \text { LLD } & \text { Limb length discrepancy } \\ \text { mSV } & \text { Millisievert } \\ \text { MRI } & \text { Magnetic Resonance Imaging } \\ & \end{array}$

\section{References}

1. Koettstorfer, J.; Hofbauer, M.; Wozasek, G.E. Successful limb salvage using the two-staged technique with internal fixation after osteodistraction in an effort to treat large segmental bone defects in the lower extremity. Arch. Orthop. Trauma Surg. 2012, 132, 1399-1405. [CrossRef]

2. Adibi, A.; Krishnam, M.S.; Dissanayake, S.; Plotnik, A.N.; Mohajer, K.; Arellano, C.; Ruehm, S.G. Computed tomography angiography of lower extremities in the emergency room for evaluation of patients with gunshot wounds. Eur. Radiol. 2014, 24, 1586-1593. [CrossRef]

3. Braunstein, E.M.; Goldstein, S.A.; Ku, J.; Smith, P.; Matthews, L.S. Computed tomography and plain radiography in experimental fracture healing. Skelet. Radiol. 1986, 15, 27-31. [CrossRef] 
4. $\quad$ Etlik, O.; Temizöz, O.; Doğan, A.; Kayan, M.; Arslan, H.; Unal, O. Three-Dimensional Volume Rendering Imaging in Detection of Bone Fractures. Electron. J. Gen. Med. 2004, 1, 48-52. [CrossRef]

5. Kopp, A.F.; Klingenbeck-Regn, K.; Heuschmid, M.; Kuttner, A.; Ohnesorge, B.; Flohr, T.; Schaller, S.; Claussen, C.D. Multislice Computed Tomography: Basic Principles and Clinical Applications. Eelectromedica 2000, 2, 94-105.

6. Busquéts, A.R.; Acosta, J.A.; Colón, E.; Alejandro, K.V.; Rodríguez, P. Helical Computed Tomographic Angiography for the Diagnosis of Traumatic Arterial Injuries of the Extremities. J. Trauma Inj. Infect. Crit. Care 2004, 56, 625-628. [CrossRef]

7. Bogdan, M.A.; Klein, M.B.; Rubin, G.D.; McAdams, T.R.; Chang, J. CT angiography in complex upper extremity reconstruction. J. Hand Surg. 2004, 29, 465-469. [CrossRef] [PubMed]

8. Schmidle, G.; Rieger, M.; Klauser, A.; Thauerer, M.; Hoermann, R.; Gabl, M. Intraosseous rotation of the scaphoid: Assessment by using a 3D CT model-An anatomic study. Eur. Radiol. 2014, 24, 1357-1365. [CrossRef]

9. Mazziotti, S.; Blandino, A.; Gaeta, M.; Bottari, A.; Sofia, C.; D’Angelo, T.; Ascenti, G. Postprocessing in Maxillofacial Multidetector Computed Tomography. Can. Assoc. Radiol. J. 2015, 66, 212-222. [CrossRef] [PubMed]

10. Kuszyk, B.S.; Heath, D.G.; Bliss, D.F.; Fishman, E.K. Skeletal 3-D CT: Advantages of volume rendering over surface rendering. Skelet. Radiol. 1996, 25, 207-214. [CrossRef] [PubMed]

11. Chae, M.P.; Lin, F.; Spychal, R.T.; Hunter-Smith, D.; Rozen, W.M. 3D-Printed haptic "Reverse" models for preoperative planning in soft tissue reconstruction: A case report. Microsurgery 2014, 35, 148-153. [CrossRef] [PubMed]

12. Pretorius, E.S.; Fishman, E.K. Volume-rendered three-dimensional spiral CT: Musculoskeletal applications. Radiographics 1999, 19, 1143-1160. [CrossRef] [PubMed]

13. Christner, J.A.; Kofler, J.M.; McCollough, C.H. Estimating Effective Dose for CT Using Dose-Length Product Compared with Using Organ Doses: Consequences of Adopting International Commission on Radiological Protection Publication 103 or Dual-Energy Scanning. Am. J. Roentgenol. 2010, 194, 881-889. [CrossRef]

14. Saltybaeva, N.; Jafari, M.E.; Hupfer, M.; Kalender, W.A. Estimates of Effective Dose for CT Scans of the Lower Extremities. Radiology 2014, 273, 153-159. [CrossRef]

15. Cross, T.M.; Smart, R.C.; Thomson, J.E.M. Exposure to Diagnostic Ionizing Radiation in Sports Medicine: Assessing and Monitoring the Risk. Clin. J. Sport Med. 2003, 13, 164-170. [CrossRef]

16. Griffiths, H.J. 1990 Recommendations of the International Commission on Radiological Protection. Annals of the ICRP Publication 60. Radiology 1992, 182. [CrossRef]

17. ICRP. The 2007 Recommendations of the International Commission on Radiological Protection. Ann. ICRP 2007, 37, 1-332. [CrossRef]

18. Zhao, L.; Fan, Q.; Venkatesh, K.P.; Park, M.S.; Song, H.R. Objective Guidelines for Removing an External Fixator after Tibial Lengthening Using Pixel Value Ratio: A Pilot Study. Clin. Orthop. Relat. Res. 2009, 467, 3321-3326. [CrossRef]

19. Sabharwal, S.; Kumar, A. Methods for Assessing Leg Length Discrepancy. Clin. Orthop. Relat. Res. 2008, 466, $2910-2922$. [CrossRef]

20. Buck, F.M.; Guggenberger, R.; Koch, P.P.; Pfirrmann, C. Femoral and Tibial Torsion Measurements With 3D Models Based on Low-Dose Biplanar Radiographs in Comparison with Standard CT Measurements. Am. J. Roentgenol. 2012, 199, W607-W612. [CrossRef]

21. Mettler, F.A.; Huda, W.; Yoshizumi, T.T.; Mahesh, M. Effective Doses in Radiology and Diagnostic Nuclear Medicine: A Catalog. Radiology 2008, 248, 254-263. [CrossRef]

22. Radzi, S.; Cowin, G.; Robinson, M.; Pratap, J.; Volp, A.; Schuetz, M.A.; Schmutz, B. Metal artifacts from titanium and steel screws in CT, 1.5T and 3T MR images of the tibial Pilon: A quantitative assessment in 3D. Quant. Imaging Med. Surg. 2014, 4, 163-172. [CrossRef] [PubMed]

23. Elsissy, P.; Akpolat, Y.T.; Chien, A.; Cheng, W.K. MRI evaluation of the knee with non-ferromagnetic external fixators: Cadaveric knee model. Eur. J. Orthop. Surg. Traumatol. 2015, 25, 933-939. [CrossRef]

24. Mahnken, A.H.; Staatz, G.; Hermanns, B.; Gunther, R.W.; Weber, M. Congenital pseudarthrosis of the tibia in pediatric patients: MR imaging. AJR Am. J. Roentgenol. 2001, 177, 1025-1029. [CrossRef]

25. Maffulli, N.; Hughes, T.; Fixsen, J.A. Ultrasonographic monitoring of limb lengthening. J. Bone Jt. Surg. Br. Vol. 1992, 74, 130-132. [CrossRef] [PubMed]

26. Perandini, S.; Faccioli, N.; Zaccarella, A.; Re, T.; Mucelli, R.P. The diagnostic contribution of CT volumetric rendering techniques in routine practice. Indian J. Radiol. Imaging 2010, 20, 92-97. [CrossRef] [PubMed]

27. Schnarkowski, P.; Rédei, J.; Peterfy, C.G.; Weidenmaier, W.; Mutschler, W.; Arand, M.; Reiser, M.F. Tibial shaft fractures: Assessment of fracture healing with computed tomography. J. Comput. Assist. Tomogr. 1995, 19, 777-781. [CrossRef] [PubMed]

28. Buckley, R.; Mohanty, K.; Malish, D. Lower limb malrotation following MIPO technique of distal femoral and proximal tibial fractures. Injury 2011, 42, 194-199. [CrossRef]

29. Say, F.; Bulbul, M. Findings related to rotational malalignment in tibial fractures treated with reamed intramedullary nailing. Arch. Orthop. Trauma Surg. 2014, 134, 1381-1386. [CrossRef] [PubMed]

30. Bhattacharyya, T.; Bouchard, K.A.; Phadke, A.; Meigs, J.B.; Kassarjian, A.; Salamipour, H. The accuracy of computed tomography for the diagnosis of tibial non-union. J. Bone Jt. Surg. Am. Vol. 2006, 88, 692-697.

31. Liodakis, E.; Liodaki, E.; Krettek, C.; Citak, M.; Gaulke, R.; Konstantinidis, L.; Kenawey, M. Can the viability of a non-union be evaluated using SPECT/CT? A preliminary retrospective study. Technol. Health Care 2011, 19, 103-108. [CrossRef] 
32. Huurman, W.W.; Jacobsen, F.S.; Anderson, J.C.; Chu, W.K. Limb-length discrepancy measured with computerized axial tomographic equipment. J. Bone Jt. Surg. Am. Vol. 1987, 69, 699-705. [CrossRef]

33. Sabharwal, S.; Zhao, C.; McKeon, J.J.; McClemens, E.; Edgar, M.; Behrens, F. Computed Radiographic Measurement of LimbLength DiscrepancyFull-Length Standing Anteroposterior Radiograph Compared with Scanogram. J. Bone Jt. Surg. Am. Vol. 2006, 88, 2243-2251. [CrossRef]

34. Huda, W.; Ogden, K.M.; Khorasani, M.R. Converting Dose-Length Product to Effective Dose at CT. Radiology 2008, $248,995-1003$. [CrossRef] [PubMed]

35. Vilar-Palop, J.; Vilar, J.; Hernandez-Aguado, I.; Gonzalez-Alvarez, I.; Lumbreras, B. Updated effective doses in radiology. J. Radiol. Prot. 2016, 36, 975-990. [CrossRef] [PubMed]

36. Biswas, D.; Bible, J.E.; Bohan, M.; Simpson, A.K.; Whang, P.G.; Grauer, J.N. Radiation Exposure from Musculoskeletal Computerized Tomographic Scans. J. Bone Jt. Surg. Am. Vol. 2009, 91, 1882-1889. [CrossRef] [PubMed]

37. Kovacs, W.C.; Yao, J.; Bluemke, D.A.; Folio, L.R. Opportunities to Reduce CT Radiation Exposure, Experience Over 5 Years at the NIH Clinical Center. Radiat. Prot. Dosim. 2017, 175, 482-492. [CrossRef]

38. Su, A.W.; Hillen, T.J.; Eutsler, E.P.; Bedi, A.; Ross, J.R.; Larson, C.; Clohisy, J.C.; Nepple, J.J. Low-Dose Computed Tomography Reduces Radiation Exposure by 90\% Compared with Traditional Computed Tomography Among Patients Undergoing HipPreservation Surgery. Arthrosc. J. Arthrosc. Relat. Surg. 2019, 35, 1385-1392. [CrossRef]

39. Yi, J.W.; Park, H.J.; Lee, S.Y.; Rho, M.H.; Hong, H.P.; Choi, Y.J.; Kim, M.S. Radiation dose reduction in multidetector CT in fracture evaluation. Br. J. Radiol. 2017, 90, 20170240. [CrossRef]

40. Jonsson, A.; Herrlin, K.; Jonsson, K.; Lundin, B.; Sanfridsson, J.; Pettersson, H. Radiation dose reduction in computed skeletal radiography. Acta Radiol. 1996, 37, 128-133. [CrossRef]

41. Song, O.K.; Chung, Y.E.; Seo, N.; Baek, S.-E.; Choi, J.-Y.; Park, M.-S.; Kim, M.-J. Metal implants influence CT scan parameters leading to increased local radiation exposure: A proposal for correction techniques. PLoS ONE 2019, 14, e0221692. [CrossRef] [PubMed]

42. Luechinger, R.; Boesiger, P.; Disegi, J. Safety evaluation of large external fixation clamps and frames in a magnetic resonance environment. J. Biomed. Mater. Res. Part B Appl. Biomater. 2007, 82, 17-22. [CrossRef] [PubMed] 